\title{
PEMANFAATAN BASIS DATA ORACLE PADA SISTEM INFORMASI WORK ORDER PADA PT XYZ DI JAKARTA TIMUR
}

\author{
Hendro Purwoko \\ Program Studi Informatika \\ Universitas Indraprasta PGRI \\ hendroprwk08@gmail.com
}

\begin{abstract}
Abstrak - Kemampuan basis data Oracle dapat bekerja pada banyak platform merupakan salah satu fasilitas yang dimanfaatkan untuk menyimpan data dengan membuatsubroutine sehinggadalam melakukan eksekusi data menjadi cepat. Kemampuan tersebut dimanfaatkan untuk membangun basis data pada Sistem Informasi Work Order Pada PT XYZ di Jakarta Timur yang bergerak pada bidang Jasa Perbaikan Alat Kesehatan di Rumah Sakit,dengan menerapkan metode Rapid Application Development agar setiap tahapan dapat langsung memproses feedback. Hasil dari pemanfaatan Oracle sebagai Basis Data mampu mendukung kinerja PT XYZ dalam melayani konsumen dengan ratusan transaksi perhari secara cepat dan mudah diakses oleh aplikasi lain yang memiliki beragam bahasa pemprograman.
\end{abstract}

Keywords - Oracle, basis data, rapid application development, work order

\section{PENDAHULUAN}

Oracle merupakan salah satu aplikasi basis data relasional yang dapat digunakan sebagai media penyimpan datadi berbagai platform. Teknologi clientserver pada Oracle merupakan salah satu Database Management System (DBMS) yang lengkap [1], salah satu kemampuan yang dapat dimanfaatkan oleh pengembang aplikasi dan database engineer adalah pembuatan query atau perintah untuk menampilkan data dari database dengan mengambil dari tabel-tabel yang berelasi[2] dan melakukan operasi-operasi lainnya dengan kode yang mudah dipahami.

Kemampuanbasis data Oracle tersebut dimanfaatkanuntuk membangun basis data pada Sistem Informasi Work Order Pada PT XYZ di Jakarta Timur yang bergerak pada bidang Jasa Perbaikan Alat Kesehatan di Rumah Sakit seluruh Indonesia yang saat ini proses operasi kerja pada perusahaan masih menggunakan aplikasi perkantoran yang tak efisien dan menimbulkan banyak permasalahan seperti: pemberian harga pada customeryang tak dapat terekam dengan baik, lamanya waktu untuk membuat laporan kerja bulanan atau tahunan serta staf juga kesulitan untuk melihat histori perubahan harga jasa dan alat yang digunakan.

Pembangunan basis data inimenerapkanmetode Rapid Application Development agar proses masingmasing tahapan berkesinambungan dan dapat langsung memproses feedback. Hasil dari pemanfaatan Oracle sebagai Basis Data mampu mendukung kinerja PT XYZ dalam melayani konsumen dengan ratusan transaksi perharisecara cepat dan mudah diakses oleh aplikasi lainyang memiliki beragam bahasa pemprograman dengan menyajikan sub routine yang dapat mengoptimalkan waktu eksekusi data.

\section{TINJAUAN PUSTAKA}

A. Oracle

Oracle adalah database relasional yang terdiri dari kumpulan data dalam suatu sistem manajemen basis data RDBMS (Relational Data Base Management System) yang multi-platform. Basis data Oracle ini pertama kali dikembangkan oleh Larry Ellison, Bob Miner dan Ed Oates lewat perusahaan konsultasinya bernama Software Development Laboratories (SDL) pada tahun 1977. Pada tahun 1983, perusahaan ini berubah nama menjadi Oracle Corporation sampai sekarang. Server Oracle berisi Oracle Instance dan Oracle Database, dimana Oracle Instance berisi struktur memory yang disebut dengan system-globalarea (SGA) dan background-process yang dipergunakan oleh server Oracle untuk mengatur database [1].

\section{B. Work Order}

Work Order merupakan tugas atau pekerjaan bagi pelanggan, yang dapat dijadwalkan atau ditugaskan kepada seseorang. Perintah semacam itu mungkin berasal dari permintaan pelanggan atau dibuat secara internal di dalam organisasi [5] Work Order juga dapat dibuat sebagai tindak lanjut dari Inspeksi atau Audit. Work Order dapat berisi satu atau beberapa hal berikut: Instruksi, Perkiraan biaya, Formulir, Tanggal dan waktu untuk melaksanakan perintah kerja, Informasi tentang lokasi dan entitas untuk melaksanakan perintah kerja dan orang yang diberi tugas kerja ditugaskan. Pemberian beban kerja harus sesuai dan memenuhi agar hak-haknya [7].

\section{METODE PENELITIAN}

Metode yang digunakan dalam pembangunan basis data adalah Rapid Application Development yang lebih cepat dan efisien dibandingkan metode 
tradisional atau dikenal dengan Metode Water Fall yang memiliki alur kerja berurutan.

Page | 118
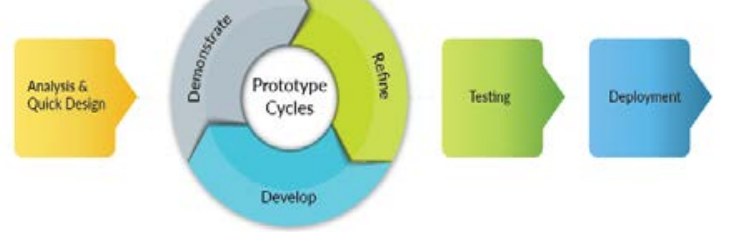

Gbr 1. Metode Rapid Application Development

Metode Rapid Application Developement memiliki alur yang berkesinambungan saat membangun prototipe, setiap feedback yang masuk dapat langsung dieksekusi hingga sistem yang dibuat berfungsi dengan baik.

TABEL 1

PENERAPAN METODE

RAPID APPLICATION DEVELOPMENT

\begin{tabular}{|c|l|}
\hline Tahap & \multicolumn{1}{c|}{ Pelaksanaan } \\
\hline $\begin{array}{c}\text { Analysis \& } \\
\text { Quick } \\
\text { Design }\end{array}$ & $\begin{array}{l}\text { Menganalisa kebutuhan tabel, kolom, tipe data } \\
\text { juga User Management yang akan diterapkan } \\
\text { pada sistem. Untuk mempercepat proses } \\
\text { eksekusi maka perlu dilakukan pembuatan } \\
\text { View, Procedure dan Trigger agar } \\
\text { memudahkan perancang sistem. }\end{array}$ \\
\hline Develop & $\begin{array}{l}\text { Menyatakan hasil dari tahap sebelumnya } \\
\text { menjadi basis data yang berelasi. }\end{array}$ \\
\hline Refine & $\begin{array}{l}\text { Melakukan koreksi dan pemeriksaan lebih } \\
\text { lanjut agar basis data siap digunakan. }\end{array}$ \\
\hline Demonstrate & $\begin{array}{l}\text { Menjalankan seluruh Query yang telah dibuat } \\
\text { untuk memastikan tak ada kesalahan kode }\end{array}$ \\
\hline Testing & $\begin{array}{l}\text { Menerapkan Query basis data dengan aplikasi } \\
\text { yang sedang dibangun dan melihat tingkat } \\
\text { keefektivitasan. }\end{array}$ \\
\hline Deployment & $\begin{array}{l}\text { Penyebaran basis data dengan melakukan } \\
\text { instalasi pada server PT XYZ. }\end{array}$ \\
\hline
\end{tabular}

\section{HASIL DAN PEMBAHASAN}

Tahap awal dalam menggunakan basis data Oracle adalah masuk melalui akun System dan membuat tablespace dengan menambahkan fasilitas penambahan ukuran secara otomatis.

create tablespace dbworkorder datafile 'dbworkorder' size 10M autoextend on;

Kemudian membuat pengguna basis data sekaligus memberikan hak akses kepada pengguna yang berlaku sebagai administrator.

create user admn identified by orcl default tablespace dbworkorder;

grant create session, connect, resource, dba to admn
Proses selanjutnya adalah login menggunakan akun yang telah dibuat dilanjutkan dengan pembuatan tabel yang berelasi melalui primary key dan foreign key, pada sistem work order ini menggunakan beberapa table, yaitu: Pegawai, Jasa, Alat, WorkOrder,WOJasa, WOAlat dan WOPegawai yang dibuat sesuai dengan struktur yang tergambar pada ERModel dibawah ini.

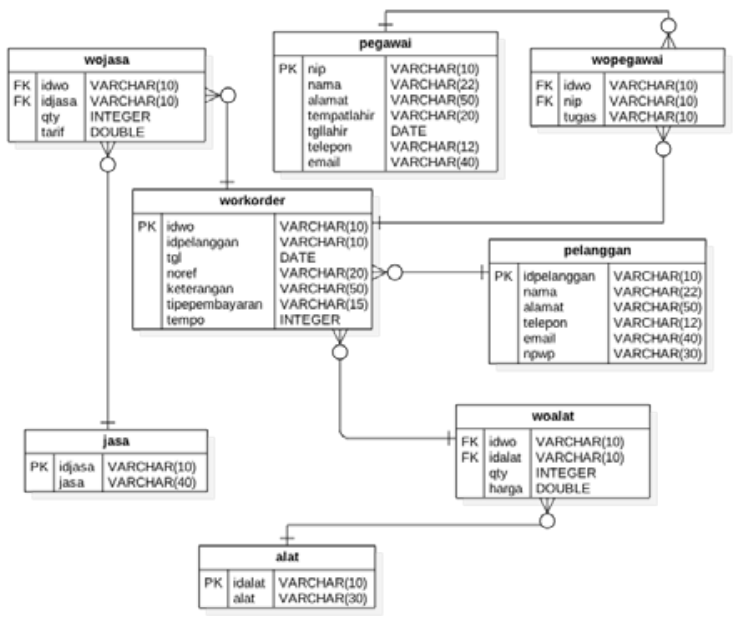

Gbr 2. Entity Relationship Model

Ada beberapa kode pada basis data yang umum dilakukan untuk optimalisasi yaitu: view, procedure, function dan trigger namun tak semuanya harus diterapkan hal ini melihat dari kebutuhan dalammengembangkan aplikasi.

Procedure merupakan sub routine yang berisi statement sehingga semua daya hanya berjalan pada sisi server saja karena telah disimpan dalam database schema dan tak perlu melakukan parsing yang memakan waktu lagi saat menjalankan query. Pada sistem ini ada beberapaprocedure untuk melakukan input datawork order yang akan mendapatkan beban paling besar diantara semua tabel:

1. Procedure input table work order create or replace procedure pworkorder

(

p_idwo in varchar,

p_idpelanggan in varchar,

p_tgl in date,

p_noref in varchar,

p_keterangan in varchar,

p_tipepembayaran in varchar, )

p_tempo in number

as

begin

insert into workorder values

( $p \_i d w o, p \_i d p e l a n g g a n, p \_t g l$,

p_noref, p_keterangan,

p_tipepembayaran, p_tempo);

end; 


\section{Procedure input table wojasa}

create or replace procedure pwojasa (

p_idwo in varchar,

p_idjasa in varchar,

Page | 119

)

p qty in number

p_tarif in number

as

begin

insert into wojasa values (p_idwo, p_idjasa, p_qty, p_tarif); end;

3. Procedure input table woalat

create or replace procedure pwoalat (

p_idwo in varchar,

p_idalat in varchar,

p_qty in number,

)

p_harga in number

as

begin

insert into woalat values (p_idwo,

p_idalat, p_qty, p_harga);

end;

4. Procedure input table wopegawai

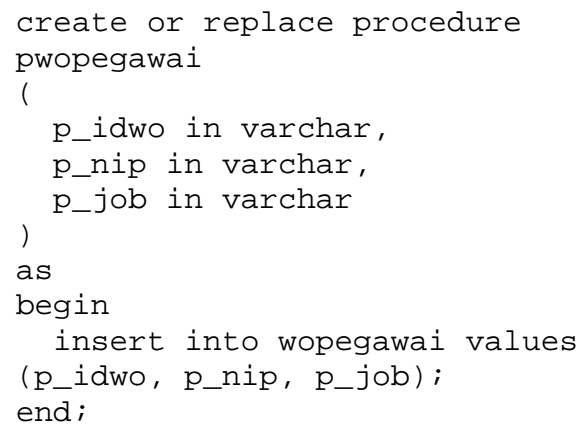

Jenis Sub routine lain yaitu viewuntuk meringkas kode ketika menampilkan data yang relevan dengan menggunakan subquery dan atau joinjika tabel memiliki relasi dengan tabel lain. Adapun view yang dibutuhkan adalah sebagai berikut:

1. Menampilkan order berdasarkan pelanggan pertahun dan perbulan dengan query sebagai berikut:

create or replace view

vorderpelanggan as

select

extract (year from tgl) as tahun, extract (month from tgl) as bulan, idwo,

idpelanggan,

(select nama from pelanggan where pelanggan. idpelanggan $=$

workorder.idpelanggan ) as nama, (select case when sum(qty * tarif) is null then $\odot$ else sum(qty * tarif) end from wojasa where wojasa.idwo = workorder.idwo) as jasa, (select case when sum(qty * harga) is null then $\odot$ else sum(qty * harga) end from woalat where woalat.idwo = workorder.idwo) as alat (select case when sum(qty * tarif) is null then $\odot$ else sum(qty * tarif) end from wojasa where wojasa.idwo = workorder.idwo) +

(select case when sum(qty * harga) is null then $\odot$ else sum(qty * harga) end from woalat where woalat.idwo = workorder.idwo) as Jumlah from workorder

Contoh hasil keluaran dari kode diatas adalah:

TABEL 2

HASIL KELUARAN DATA ORDER

BERDASARKAN PELANGGAN PERTAHUN DAN PERBULAN

\begin{tabular}{|llllllll|}
\hline TAHUN & BULAN & IDWO & IDPELANGGAN & \multicolumn{1}{c}{ NAMA } & JASA & ALAT & JUMLAH \\
\hline 2018 & 2 & W0001 & P002 & Kinik Permata Karta & 8415000 & 0 & 8415000 \\
\hline 2018 & 2 & W0002 & P003 & Puskesmas Indart Winangun & 0 & 7600000 & 7600000 \\
\hline 2018 & 2 & W0003 & P002 & Kinik Permata Karta & 2080000 & 0 & 2080000 \\
\hline 2018 & 3 & W0004 & P001 & RS Budi Warman & 8830000 & 440690000 & 449520000 \\
\hline 2018 & 4 & W0005 & P005 & RSUD Mawardi & 2940000 & 0 & 2940000 \\
\hline 2018 & 4 & W0006 & P005 & RSUD Mawardi & 1600000 & 489400000 & 491000000 \\
\hline 2018 & 4 & W0007 & P002 & Klinik Permata Karta & 0 & 20300000 & 20300000 \\
\hline
\end{tabular}

2. Merekap Total Order pertahun dan perbulan
create or replace view vordertahunbulan as select tahun, bulan, sum(jasa) as jasa, sum(alat)as alat, sum(jumlah) as jumlah from vorderpelanggangroup by tahun, bulan

Hasil dari kode pembuatan view diatas adalah:

TABEL 3

HASIL KELUARAN REKAP ORDER PELANGGAN PERTAHUN DAN PERBULAN

\begin{tabular}{|lllll|}
\hline TAHUN & BULAN & JASA & \multicolumn{1}{c}{ ALAT } & JUMLAH \\
\hline 2018 & 4 & 4540000 & 509700000 & 514240000 \\
\hline 2018 & 2 & 10495000 & 7600000 & 18095000 \\
\hline 2018 & 3 & 8830000 & 440690000 & 449520000 \\
\hline
\end{tabular}

Dari tabel diatas terlihat bahwa total jasa, alat serta jumlah ditampilkan dengan jelas sehingga dapat mempermudah kinerja pemprogram.

3. Menampilkan historikal tarif jasa yang pernah ditawarkan kepada pelanggan berdasarkan id, hal ini dibuat mengingat penetapan tarif dapat berubah sesuai negosiasi dan lokasi pelanggan

create or replace view vtarifjasa as select wojasa.idjasa, jasa.jasa, wojasa.tarif

from wojasa inner join jasa 
on wojasa.idjasa $=$ jasa.idjasa

order by idjasa asc

Hasil olah query diatas terbentuk menjadi tabel dibawah ini:

Page | 120

HASIL KELUARAN

HISTORIKAL PEMBERIAN TARIF KEPADA PELANGGAN

\begin{tabular}{|lll|}
\hline ID JASA & \multicolumn{1}{c}{ JASA } & \multicolumn{1}{c|}{ TARIF } \\
\hline J001 & $\mathrm{Pb}$. Patient Monitor & 400000 \\
\hline J002 & Penggantian komponen & 450000 \\
\hline J002 & Penggantian komponen & 200000 \\
\hline J003 & $\mathrm{Pb}$. Spirometer & 1230000 \\
\hline J004 & $\mathrm{Pb}$. Threadmill & 825000 \\
\hline J004 & $\mathrm{Pb}$. Threadmill & 900000 \\
\hline
\end{tabular}

4. Menampilkan historikal harga alat yang ditawarkan kepada pelanggan berdasarkan id memiliki fungsi untuk melihat historikal pemberian harga yang diberikan pada pelanggan

create or replace view vhargaalat as select woalat.idalat, alat.alat, woalat. harga

from woalat inner join alat on woalat . idalat = alat . idalat order by idalat asc

Hasil keluaran kode diatas adalah:

TABEL 5

HASIL KELUARAN HISTORIKAL PEMBERIAN HARGA ALAT KEPADA PELANGGAN

\begin{tabular}{|c|c|c|}
\hline IDALAT & ALAT & HARGA \\
\hline A001 & Selimut & 150000 \\
\hline A001 & Selimut & 150000 \\
\hline A002 & Trolly & 150000 \\
\hline A004 & Otoskop & 3200000 \\
\hline A004 & Otoskop & 3700000 \\
\hline A005 & Stetoskop & 2500000 \\
\hline A007 & Alat USG & 12600000 \\
\hline A007 & Alat USG & 12800000 \\
\hline
\end{tabular}

Untuk mempermudah pemprogram dalam menampilkan data yang spesifik dan dapat di selipkan pada sebuah query perlu dibuatkan function yang berguna untuk mendapatkan total order berdasarkan idwo, query tersebut adalah:

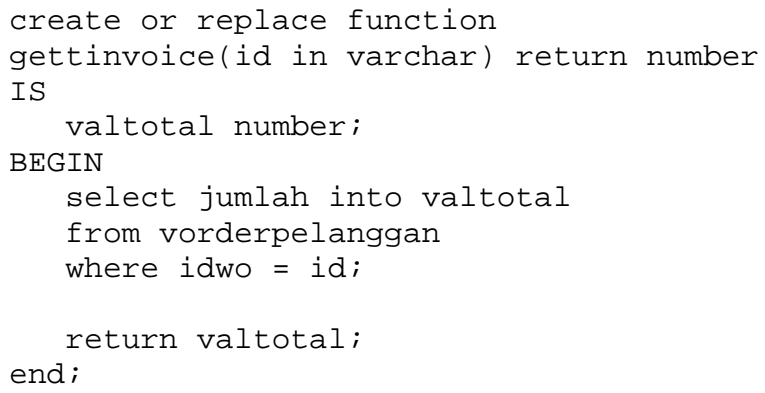


[5] J. I. Maanari, R. Sengkey, ST., MT. , Ir. H. F. Wowor, M.Kom., Y. D. Y. Rindengan, ST., MM., Msc. 2013. Perancangan Basis Data Perusahaan Distribusi dengan Menggunakan Oracle. e-journal Teknik Elektro dan Komputer (2013)

[6] Work Order. 2018. Retrieved Mei 20, 2018, From Https://En.Wikipedia.Org/Wiki/Work_Order

Page | 121 [7] Sutabri, T. 2012. Analisis Sistem Informasi. Jakarta: Andi.

[8] Hartono, B. 2013. Sistem Informasi Manajemen Berbasis Komputer. Jakarta: Rineka Cipta.

[9] Syamsul. 2012. Rancang Bangun Sistem Pendukung Keputusan Pembagian Beban Kerja Dosen (BKD) Berbasis Logika Fuzzy. Jurnal Litek, 9(2), 124-133. 